\title{
The evolution of mush porosity during reactive porous flow
}

\author{
MATTHEW L. M. GLEESON ${ }^{1}$, PAULA \\ ANTOSHECHKINA $^{2}$ AND JOHAN LISSENBERG ${ }^{1}$
}

${ }^{1}$ Cardiff University

${ }^{2}$ Caltech

Presenting Author: gleesonm1@cardiff.ac.uk

The mush paradigm can explain several of the geochemical and geophysical features of igneous systems that are inconsistent with the presence of large, liquid-rich magma chambers. However, the dominance of melt-poor regions, where an interlocking crystal framework results in a high bulk viscosity, restricts magma eruptability and leads to fundamental questions about the dynamics of magmatic systems. One of these concerns the mechanisms of magma extraction from crystal-rich regions to form melt-dominated, and potentially eruptible magma reservoirs.

To date, magma transport within magmatic mushes has been studied through detailed petrological investigations of magmatic cumulates and reservoir-scale numerical simulations that include only basic chemical parametersations. Both methods have determined that reactive flow, where a percolating melt phase continuously reacts with a surrounding crystal framework, is important in mush-rich reservoirs. However, there is a large disconnect between the petrological investigations and the dynamical models used to simulate melt transport. To bridge this divide and provide more detailed constraints on the mechanisms and consequences of porous flow within mush-dominated magma storage regions, we design new models to describe the chemical interaction between basaltic melt and mush during magma transport. Our models utilize the MELTS thermodynamic packages and simulate the chemical and physical consequences of melt-mush reaction under a wide range of conditions relevant to volcanic systems.

Our models reproduce petrological observations made in natural crystal mushes as well as experimental data, indicating that they successfully capture the dynamics of reactive flow. Critically, we find that primitive basaltic lavas, that is, lavas that are saturated in olivine \pm plagioclase, drive an increase in the mush porosity during melt-mush reaction. This porosity-opening behaviour could lead to the formation of high porosity melt channels within the crystal mush, and thus a substantial increase in the volume of magma that can be transported through mushdominated magma storage regions. This is in contrast to reactive flow of more evolved, three-phase saturated basalt, which results in progressively decreasing porosity. We conclude that that melt composition, as well as the composition and temperature of the mush itself, has a substantial influence on the evolution of porosity within magmatic mushes. 